\title{
História da Educação em perspectiva transnacional
}

History of Education in a transnational perspective

Historia de la educación bajo el enfoque transnacional

Carolina Mostaro Neves da Silva

Universidade de São Paulo (Brasil)

Bolsista da Fundação de Amparo à Pesquisa de São Paulo

https://orcid.org/0000-0003-0853-6726

http://lattes.cnpq.br/8957578717474377

carolmostaro@yahoo.com.br

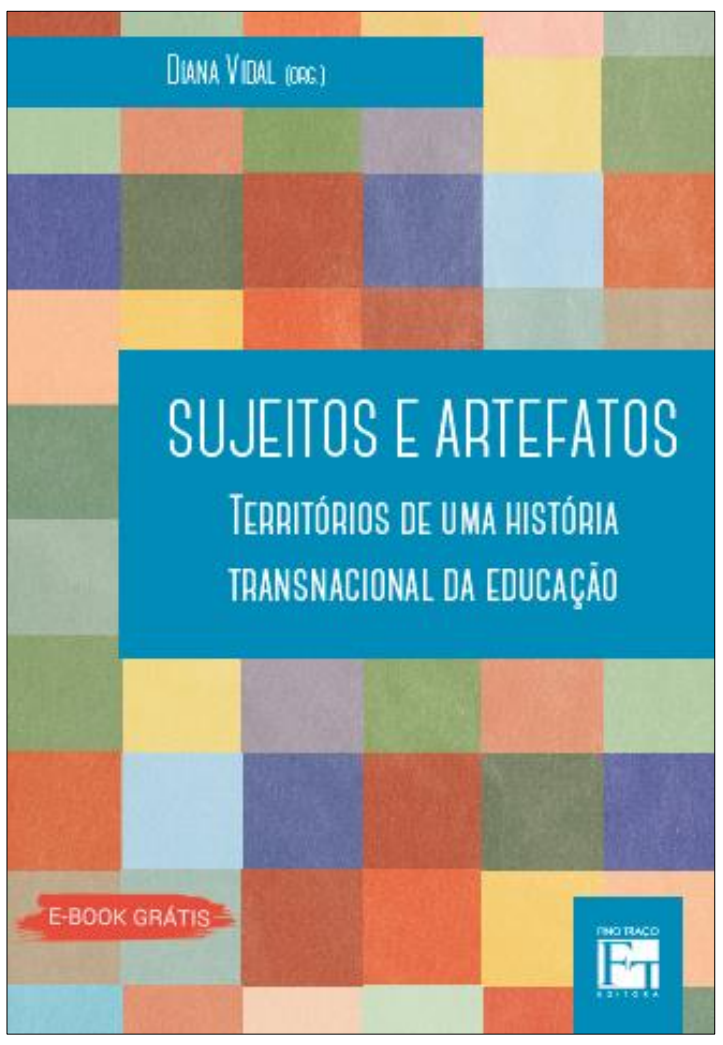

VIDAL, Diana Gonçalves (org.). Sujeitos $e$ Artefatos: territórios de uma história transnacional da educação. Belo Horizonte: Fino Traço, 2020. 
Nos últimos anos, é crescente o interesse por abordagens transnacionais no campo historiográfico. Diante da frequência com que o termo tem aparecido em títulos de livros, artigos e palavras-chave, Struck, Ferris e Revel (2011) levantam a possibilidade de a história transnacional representar uma mudança metodológica significativa na historiografia, tal como aconteceu com a história social, a partir dos anos de 1950, e com a micro-história, nos anos de 1970 e 1980. Não surpreende, portanto, que venha recebendo atenção de pesquisadoras e pesquisadores do campo da História da Educação, que, pelo menos desde os anos oitenta, têm buscado o alinhamento e o diálogo com a historiografia.

Demonstrando o potencial das abordagens transnacionais para investigações que tomam como tema a educação e a escola, em suas múltiplas perspectivas e interfaces, foi recentemente publicado, em formato E-book, pela Fino Traço Editora, o livro Sujeitos e Artefatos: territórios de uma história transnacional da educação, organizado por Diana Vidal. A obra é parte da Coleção Estudos Brasileiros, do Instituto de Estudos Brasileiros, e resultado de um conjunto de pesquisas que, desenvolvidas no âmbito do projeto temático Saberes e práticas em fronteiras: por uma história transnacional da educação (1810-...), privilegiam os movimentos, a circulação, os intercâmbios de sujeitos e objetos elucidativos de experiências e processos educacionais, ao longo dos séculos XIX e XX'

Dividido em duas partes, o livro é formado por seis capítulos que congregam uma ampla variedade temática e mobilizam um conjunto diversificado de fontes, tais como livros, manuais, imprensa periódica e especializada, catálogos de divulgação de produtos e fotografias. A primeira parte, construída em torno de viagens de educadores e educadoras do Brasil e dos Estados Unidos, é marcada, do ponto de vista teórico, pela mobilização da categoria de redes/networks, trazendo como referência principal o trabalho de Fuchs (2007); destacam-se as conexões e articulações estabelecidas em diferentes escalas, nacionais e internacionais, locais e individuais. A segunda parte do livro traz duas pesquisas sobre artefatos que materializam práticas e conhecimentos produzidos em determinado lugar, mas que, ao circularem por espaços múltiplos, foram apropriados e ressignificados. Do ponto de vista espacial, as narrativas se desenvolvem em torno de dois espaços nacionais, Brasil e Estados Unidos. Entretanto, aparecem outras possibilidades de itinerários investigativos, como a relações Estados Unidos/ França, indicadas por Alcântara, em seu capítulo sobre a carteira escolar, ou o itinerário Estados Unidos/América do Sul/Itália, entrelaçados por Rafaela Rabello, no capítulo quatro.

A esse respeito, as concepções de território e espaço, analisadas por Vidal (2020, p. 10) na introdução, são fundamentais para que se compreenda o ponto de partida das autoras e do autor dessa obra: “o território é 'integralmente espaço-temporal', construído por meio de interações nas quais a coexistência de ideias é fundamental para a compreensão de sua heterogeneidade. Dessa maneira, o espaço consiste em uma simultaneidade de histórias". Propõe-se desnaturalizar a concepção de território fixo, demarcada pelo Estado, sustentada numa noção de espaço atemporal, delimitada pelas fronteiras físicas e simbólicas do EstadoNação. Como construtos teóricos e, portanto, históricos e sociais, território e espaço - bem como seus desdobramentos: a nação, a fronteira, as identidades etc. - podem ser apropriados como objetos nos percursos investigativos das pesquisas em história educação.

\footnotetext{
${ }^{1}$ Projeto financiado pela FAPESP (2018/26699-4) e coordenado pelas professoras Diana Vidal e Carlota Boto, com a participação de pesquisadores e estudantes de várias universidades paulistas.
} 
Outro aspecto teórico que marca a publicação é a recusa à visão dicotômica de centro e periferia, que caracterizaria o primeiro por suas funções criadora, disseminadora e condutora, em contraposição a processos de assimilação, reprodução ou aceitação nas zonas consideradas periféricas. Assume-se que as interações são movimentos múltiplos, complexos, atravessados por processos criativos, adaptativos e transformativos em diversas direções e sentidos, ainda que, nessa obra, os objetos e a ênfase das análises estejam situados, em relação ao recorte espacial, no Brasil, mais precisamente em São Paulo e no Rio de Janeiro.

O primeiro capítulo, Trajetórias da família Loureiro de Andrade na educação da infância: um debate transnacional, de autoria de Vinícius Monção, trata dos empreendimentos educativos dos Loureiro de Andrade, no final do século XIX e início do $\mathrm{XX}$, buscando identificar suas conexões com o contexto educacional internacional, com base, principalmente, em anúncios de periódicos que então circularam no Rio de Janeiro. Destacam-se as relações dessa família com missionários presbiterianos, como rede que favoreceu os intercâmbios internacionais da família, e a atuação de Maria Guilhermina Loureira de Andrade, que fez uma viagem de estudos aos Estados Unidos, entre 1883 e 1887. O texto instiga a reflexão sobre a relação entre um "mercado educacional" e a apropriação de práticas, modelos e materiais estrangeiros, como elemento significativo para o impulso dos intercâmbios internacionais, levantando a questão da educação como "negócio", tema ainda pouco explorado no campo da História da Educação.

Vivian Batista da Silva e Keila da Silva Vieira são as autoras do capítulo seguinte, Luiz Alves de Mattos e suas redes: viagens e conexões no campo educacional (1917-1990), que aborda a trajetória do educador, considerando sua formação em instituições de São Paulo, Rio de Janeiro e dos Estados Unidos, os cargos ocupados ao longo de sua carreira, bem como algumas de suas experiências de viagens e publicações. A partir da noção de redes, as autoras articulam diferentes escalas de análise e conectam a trajetória singular de Mattos ao movimento do campo educacional, identificando intercâmbios e hierarquias, articulações de referenciais estrangeiros com experiências docentes e estudos internacionais. Analisa-se a circulação internacional de uma obra de Mattos, Sumário da Didática Geral, indicando as conexões entre a trajetória do educador e uma rede educacional latino-americana. Certamente, o estudo ultrapassa a perspectiva da transferência, pela qual se transitaria de um ponto a outro, mostrando que movimentos e apropriações dão-se em múltiplas direções e distintos níveis.

Seguindo na linha das viagens, o terceiro capítulo explora a ida de sete educadoras brasileiras ao Estados Unidos, em missão de trabalho, no ano de 1930. A autora, Diana Vidal, investiga representações sociais projetadas sobre a mulher-professora, destacando a ideia do celibato pedagógico e da incompatibilidade entre casamento, maternidade e profissão, no momento em que medidas higiênicas e eugênicas buscavam garantir um padrão familiar saudável, ainda pautado no modelo cristão e patriarcal. Mostrando as disputas de representações em torno do corpo da mulher, o texto analisa a experiência da viagem como um encontro com o outro, com a alteridade, que instiga a reflexão sobre si, sobre o ser mulher, sobre o lugar social da mulher no Brasil, na medida em que as educadoras se depararam com diferentes possibilidades de inserção social feminina nas cidades estadunidenses que visitaram.

Fechando a primeira parte do livro, o capítulo A educação Sul-Americana nas narrativas de Carleton Washburne: uma análise sob a lente da política de boa vizinhança, de Rafaela Rabelo, investiga a passagem desse educador estadunidense por Equador, Chile, Paraguai e 
Brasil, em uma missão de estudo comissionada pelo Departamento de Estado dos EUA. Assumindo como referencial de análise a noção de leitura em contraponto (SAID, 2011), Rabelo conecta os escritos de Washburne a respeito da educação sul-americana à política de boa vizinhança, implementada pelos EUA, para reforçar suas relações diplomáticas com o hemisfério sul. Observam-se nos detalhes, nas sutilezas e silêncios, vestígios de uma política que visava promover a dominação cultural norte-americana, por meio de um discurso de conciliação, parceria e apoio, entrelaçando educação e diplomacia.

$\mathrm{Na}$ segunda parte do livro, em que o exercício da abordagem transnacional centra-se na circulação de objetos, Wiara Rosa Alcântara traz uma interessante investigação sobre a difusão da carteira escolar, no final do século XIX, mostrando a complexa trama de relações que envolvem, além de preceitos pedagógicos e higiênicos, sua produção, divulgação e mercado. Destacam-se movimentos de apropriação, (re)produção e transformação por meio da ação de diversos atores, como políticos, educadores e fabricantes, com distintas motivações e interesses, no processo que levou à consolidação da carteira como elemento intrínseco à escola moderna. O texto privilegia as empresas estadunidenses, hegemônicas na fabricação e no comércio de carteiras escolares, mas indica que havia produção no Brasil, onde o objeto teria ganhado novos sentidos.

No último capítulo do livro, Rachel Duarte Abdala conecta fotografia, movimento fotográfico e fotógrafos, destacando Augusto Malta e Nicolas Alagemovits, nos anos de 1920. Partindo dos debates sobre o estatuto artístico da fotografia, que mobilizaram fotógrafos de diversas regiões do mundo em torno do pictorialismo, a autora investiga a formação de grupos e associações, que promoviam reflexões, exposições e publicações, atuando como promotores e padronizadores da prática fotográfica. Por meio de manuais e periódicos, especialmente a revista Photogramma, do Photo Club Brasileiro, mostra-se a expansão do fotoclubismo no Brasil e suas conexões internacionais, com os EUA e a Europa. Em relação à circulação e ao movimento, o próprio texto encarna um trânsito, ao mostrar-se como desdobramento de uma pesquisa de história da educação que deságua na história da fotografia, território aparentemente alheio, mas que, no movimento múltiplo da investigação historiográfica, revela que o olhar para fora e para o outro é necessário para elucidar objetos de investigação aparentemente circunscritos a um determinado campo.

Pela diversidade das análises e modos de manejar as fontes, denota-se que o livro congrega pesquisas em diferentes estágios de desenvolvimento e aproximação com a abordagem transnacional. Traz, portanto, um panorama diversificado e instrutivo do exercício historiográfico com essa abordagem, que se define mais pela perspectiva de estudos que "enfatizam a importância da interação e circulação de ideias, povos, instituições ou tecnologias através das fronteiras estaduais ou nacionais e, portanto, o entrelaçamento e influência mútua de estados, sociedades ou culturas" (STRUCK; FERRIS; REVEL, 2011, p. 574), do que como um método específico de arcabouço teórico conceitual delimitado. Para o campo da História da Educação, de tradicional preferência por fontes e marcos oficiais e nacionais (GONDRA, 2005; BONTEMPI JR., 2012), a pesquisa com a abordagem transnacional tem o potencial de revelar aspectos desconhecidos e agentes invisíveis, assim como permitir revisões de interpretações tradicionais ou canônicas, construídas sob a égide de uma escrita histórica descritiva e factual. 


\section{Referências}

BONTEMPI JR., B. A história da educação na Rbep (1999-2011). Revista Brasileira de Estudos Pedagógicos, v.94, n.234, p.502-518, 2012.

FUCHS, E. Networks and the History of Education, Paedagogica Historica, v.43, n.2, p.185197, 2007. DOI: https://doi.org/10.1080/00309230701248271.

GONDRA, J.G. (Org.). Pesquisa em história da educação no Brasil. Rio de Janeiro: DP\&A, 2005.

SAID, E. Cultura e Imperialismo. São Paulo: Companhia das Letras, 2011.

STRUCK, B.; FERRIS, K.; REVEL, J. Introduction: Space and Scale. Transnational History. The International History Review, v.33, n.4, p.573-584, 2011. DOI: https://doi.org/10.1080/07075332.2011.620735.

VIDAL, D.G. (org.). Sujeitos e Artefatos: territórios de uma história transnacional da educação. Belo Horizonte: Fino Traço, 2020. 